\title{
Critical incidents as perceived by rapid response teams in emergency services*
}

\author{
Incidentes críticos percebidos pelos times de resposta rápida \\ nos atendimentos de emergência \\ Incidentes críticos percibidos por los equipos de respuesta rápida \\ en atención de emergência
}

How to cite this article:

Dias AO, Bernardes A, Chaves LDP, Sonobe HM, Grion CMC, Haddad MCFL. Critical incidents as perceived by rapid response teams in emergency services. Rev Esc Enferm USP. 2020;54:e03595. doi: https://doi.org/10.1590/S1980-220X2018027903595

\section{Alexsandro de Oliveira Dias ${ }^{1}$ \\ Andrea Bernardes ${ }^{1}$ \\ Lucieli Dias Pedreschi Chaves ${ }^{1}$ \\ Helena Megumi Sonobe ${ }^{1}$ \\ Cintia Magalhães Carvalho Grion² \\ Maria do Carmo Fernandez Lourenço Haddad ${ }^{3}$}

* Extracted from the thesis: "Atendimentos realizados por times de respostas rápidas em hospitais”, Escola de Enfermagem de Ribeirão Preto, Universidade de São Paulo, 2017.

${ }^{1}$ Universidade de São Paulo, Escola de Enfermagem de Ribeirão Preto, Programa de Pós-Graduação em Enfermagem Fundamental, Ribeirão Preto, SP, Brazil.

${ }^{2}$ Universidade Estadual de Londrina, Programa de Pós-Graduação em Ciências da Saúde, Londrina, PR, Brazil.

${ }^{3}$ Universidade Estadual de Londrina, Programa de Pós-Graduação em Enfermagem, Londrina, PR, Brazil.
Corresponding author:

Alexsandro de Oliveira Dias

Avenida Robert Koch, 60, Vila Operária

CEP 86038-350 - Londrina, PR, Brazil

alex.hu@uel.br

\begin{abstract}
Objective: To analyze two hospital emergency services, one in a public institution and another in a philanthropic one, from the perspective of rapid response team professionals in the face of positive and negative critical incidents. Method: Descriptive, exploratory, qualitative study carried with 62 health professionals. Critical Incident Technique was employed as the theoretical-methodological framework, along with Content Analysis for analyzing data. Results: Sixty-two health professionals - including 23 nurses, 20 physiotherapists and 19 doctors - took part in this study. Clusters for 89 critical incidents were obtained; 66 of them were considered positive, whereas 23 were negative. The situations associated to the provided services were discriminated in three categories: recognition of patient clinical deterioration; rapid response team activation in the unit; and time until rapid response team arrival at the ward. Conclusion: In spite of the difficulties faced by such professionals while providing care to patients who become severely ill in non-critical wards, positive reports were predominant in all categories, what legitimized this service's importance as a contribution to quality and safety of hospitalized patients.
\end{abstract}

\section{DESCRIPTORS}

Hospital Rapid Response Team; Heart Arrest. Cardiopulmonary Resuscitation; Emergency Nursing; Patient Safety. 


\section{INTRODUCTION}

Patient safety is a theme increasingly highlighted by the literature. Such a theme cannot be deemed contemporary, considering evidences of patient harm prevention dated as over 2,000 years old. The World Health Organization warns that tens of millions of patients suffer harm leading to some form of disability or death due to health care errors every year around the world. Such harm, known as Adverse Events (AE), afflict one in ten hospitalized patients ${ }^{(1)}$.

The data on AE occurrences are alarming, leading to considerable repercussion both nationally and internationally. Patient safety is currently deemed as a global priority by the world's main health organizations ${ }^{(2-3)}$.

In the last decades, there has been an increase in this debate in the health area. Care quality became a focal point - still below expectations - for both patients and professionals engaged in promoting reduction of $\mathrm{AE}$ during hospitalization ${ }^{(4)}$.

Due to recurrent $\mathrm{AE}$ episodes, the Institute for Healthcare Improvement, in the United States, has recommended the implementation of Rapid Response Teams (RRT) in hospitals as a contribution to promoting safe care to patients who become severely ill outside of Intensive Care Units (ICU).

Care to patients in severe clinical condition is activated by the unit's professional, who recognizes warning signs and activates the professionals (doctors, nurses and physiotherapists) from the RRT. The team arrives at the care area in up to three minutes to conduct interventions that become necessary due to the clinical emergency ${ }^{(5)}$.

The RRT's primary base is early detection and intervention regarding patients hospitalized in nursing wards who present critical care demands outside of ICU. In the last decades, RRT have been broadly employed in hospitals in the USA, Canada, Australia, United Kingdom ${ }^{(6)}$ and Brazil ${ }^{(7)}$.

Recent national and international studies have been providing evidence of RRT's efficacy, presenting results that are meaningful for inpatient safety, such as a reduction in cardiac arrests $(\mathrm{CA})^{(8-9)}$ or a significant decrease in patient mortality ratio ${ }^{(10)}$.

Therefore, due to the scarcity of Brazilian qualitative studies dealing with this theme, broadening the research on RRT implementation in Brazilian health institutions is necessary. Such research should include the outlook of the professionals who cooperate to provide care to patients who become severely ill in nursing wards, granting the possibility of conducting deeper analysis on the systematization of the care these teams provide.

By employing the Critical Incident Technique (CIT), as described by its proponent ${ }^{(11)}$, resorting to direct observation of RRT behavior is expected as a means to facilitate solving technical problems by understanding their influence on the emergency service of health institutions.

In view of the above, this study aims to analyze emergency care from the perspective of RRT professionals from two hospitals - one public and the other philanthropic when faced by positive and negative critical incidents.

\section{METHOD}

\section{STUdy TYPE}

This is a descriptive, exploratory, qualitative research. The theoretical-methodological framework employed was the Critical Incident Technique (CIT), which consists in procedures to collect direct human behavior observations with the purpose of facilitating their usage in solving practical problems, as well as applying broad psychological principles $^{(11)}$ to unfold the reported situations. In such situations, both positive and negative circumstances emerging from RRT attendance were identified.

Critical Incidents (CI) are relevant situations reported or observed by respondents. In the health area, CIT has been adopted as a practical method which enables researchers to apprehend health service complexity by registering the behavior of professionals in work environments ${ }^{(12)}$.

\section{SCENARIO}

This research was conducted in a public hospital located in a countryside municipality in Paraná state and a philanthropic hospital in São Paulo state. Both have been providing RRT care for ten years.

This public institution is the only high-complexity university hospital in the northern area of Paraná state and provides service exclusively to the Brazilian Unified Health System (SUS - Sistema Único de Saúde) with 307 available beds. The philanthropic one is rated as a high-complexity teaching hospital in São Paulo city which provides 469 beds. This study had no intent of comparing institutions, rather focusing on establishing how care was provided by RRT professionals in the research settings, which present similar work methods.

\section{SelECTION CRITERIA}

One opted for interviewing all health professionals from both institutions where data was collected. Thus, all doctors, nurses and physiotherapists whose experience in the RRT was equal or superior to six months have been selected, since they were considered to have taken part in emergency care. All of these agreed to participate in the study. Professionals who were on vacation or on any kind of leave have been excluded from this study.

Once the selection criteria were met, out of 76 professionals from both institutions, 62 (81.6\%) became study participants, totaling 19 doctors, 20 physiotherapists and 23 nurses.

\section{Data collection}

Data collection lasted from June to August 2017 and was conducted with RRT professionals who agreed to participate in the study.

Data collection and analysis were conducted by the main researcher, who firstly asked participants to fill out a professional identification form, followed by an interview containing two guiding questions. The respondent was asked to present a detailed report on a positive and a negative 
situation taking place during the RRT interventions in their everyday life.

The interviews lasted 20 minutes on average and were performed in an isolated environment. Their aim was identifying the features of the emergency care, the action taken by the involved professionals and the situation's outcome.

Such reports have enabled the extraction of this service's positive and negative characteristics. After due signing of previous authorization by the participants, the interviews were recorded, transcribed and analyzed by the main researcher.

\section{Data TREATMENT AND ANALYSIS}

Content analysis, as proposed by Minayo ${ }^{(13)}$, was applied to data analysis, which led to the extraction of 89 critical incidents from 62 interviews. Such analysis established three thematic categories, namely: recognition of the patient's clinical deterioration; activation of rapid response team in the unit; and time until rapid response team arrival at the ward.

Out of 89 critical incidents, RRT professionals from both institutions reported 66 situations as positively and 23 as negatively related to the emergency care.

\section{ETHICAL ASPECTS}

This study was approved by Universidade de São Paulo's School of Nursing Ethics Committee in opinion number $151 / 2014$. Norms and directives on research involving human beings were respected, with due observation of Resolution number $466 / 12$ by the National Health Council, and all participants signed the Informed Consent Form.

The participants' anonymity was ensured by identifying each of them by their professional category's (Doctor, Nurse or Physiotherapist) initial and a number assigned by interview chronological order, e.g., N1 (Nurse 1), P1 (Physiotherapist 1) or D1 (Doctor 1) and so on.

\section{RESULTS}

Sixty-two health professionals were interviewed. These include all RRT professional categories (doctors, nurses and physiotherapists). Out of those 62, 44 (71\%) were females and $34(55 \%)$ were aged 25 to 35 years. $51(82 \%)$ had 2 to 12 years of professional education and $48(78 \%)$ had concluded a specialization course.

The interviewees talked about positive and negative aspects of emergency care provided by RRT professionals in the study hospitals. From 62 interviews, 89 critical incidents, i.e., situations allowing for an analysis, were identified.

After report analysis, critical incidents were grouped into three categories, namely: recognition of patient's clinical deterioration; activation of rapid response team in the unit; and time until rapid response team arrival at the ward.

\section{RECOGNITION OF PATIENT'S CLINICAL DETERIORATION}

The category "recognition of patient's clinical deterioration" accounts for evaluation and detection by professionals in non-critical wards of patients' warning signs due to clinical deterioration.
One emphasizes the importance of detecting physiological alterations during the patient's hospitalization to enable necessary interventions favoring fast and effective joint care by staff and RRT, as in the following reports:

The last service was very positive. The ward staff have quickly recognized the patient's worsening signs and activated us immediately. When I got to the room, I noticed they had already brought the crash cart and organized the place, so we started assisting the client, who was suffering a $C A$ (N4).

Well, a recent situation I recall happened this week (...) The patient's clinical condition had deteriorated, and the unit's nurse quickly got to the room to check the call and she understood it was a CA. All of this happened very fast (P1).

The situations presented as examples show that the ward staff were able to quickly detect signs of clinical worsening, i.e., warning signs, for RRT activation, what benefitted the patients with necessary interventions performed by the multiprofessional team.

The objective of recognizing the patient's warning signs is often left unfulfilled, what the interviewees characterized as negative care, as shown by the following pieces of discourse: One service I regard as negative was when we were activated to attend a $C A$ situation (...) I think the responsible nurse should have called the RRT much earlier, because we could have performed several early interventions to keep the patient from evolving to a CA. In my opinion, this should not happen. (...) This situation was a learning experience for the sector staff, which must feel secure to activate the team as soon as they detect any kind of change in the patient's health status (D6).

The patient had a discrete postural hypotension. She reported malaise to the nursing staff and then we were activated. This undue activation has made a whole team move to the ward. If this practice is normalized, it will have impacts on care quality provided. The unit staff must recognize the patient's signs of clinical worsening more accurately and relate them to the protocol (D17).

\section{RAPID RESPONSE TEAM ACTIVATION IN THE UNIT}

The category "rapid response team activation in the unit" refers to the several ways of activating this team to direct emergency care, either by corporate cell phones, pager (or beeper), telephone extension or sound system, among others.

In both institutions, nurses in non-critical care units represented most of the professionals who activated the RRT.

The positive reports on correct RRT activation are exemplified by the following discourse:

There was a service two weeks ago when we activated the RRT in the unit; the doctor was having lunch and there was no cellphone signal in the hospital's cafeteria. So, I had to activate her by sound system. She heard the call and managed to come to the unit in two minutes. In this institution, the criteria to activate the RRT are very clear; the activation criteria and contact number were on banners fixed within the ward, in places where it can be seen by all professionals (N19).

When the RRT is activated to perform emergency care, the apparatus that is with us during office hours vibrates, directing 
us to the building and floor where the complication is happening (...) The elevator operator also has the beeper and can hold the elevator so that we can move as quickly as possible through the several buildings in the institution (D4).

In both the examples provided by the professionals, RRT activation was successful for care performance. The importance of the activation mechanism comes as noteworthy to fulfill the objective of performing services under three minutes to improve care of inpatients becoming severely ill.

In this category, there are also negative reports of RRT activation in the non-critical hospitalization unit, as shown by the following statements:

I entered the room and noticed that the patient was having a $C A$, so we started to perform cardiopulmonary resuscitation procedures. When the team's doctor arrived and asked what had occurred, the ward's nurse had no knowledge of the clinical situation; when the record was checked, they found that she was an oncological patient, not available for resuscitation. So this is a flaw in RRT activation, because until figuring out the whole situation the team had already started the service, which led to a very bad and stressful situation both to the team and a patient's relative, who had noticed all of this (P14).

Once we were activated on the floor and the patient was awake and lucid; the titular doctor told everybody that he had called the team because he needed medical help to discuss that patient's treatment. I felt embarrassed. It was disrespectful to waste the team's service. When someone activates us, they must be aware of the severity criteria in the protocol. All our action was in vain. What if another patient in a severe condition needed our care at that same moment? (D9).

It is essential that all professionals in the non-critical hospitalization unit be aware and secure regarding the RRT activation criteria adopted by the institutions, so that a false positive activation does not occur, since this leads to unnecessary action by the professionals, generating unjustified stress, as stated in the discourses above.

\section{TIME UNTIL RAPID RESPONSE TEAM ARRIVAL AT THE WARD}

The third category of critical incidents concerns "time until rapid response team arrival at the ward", which, according to the attendance protocol of both institutions, is based on a set objective of arriving within three minutes to initiate the necessary interventions after service activation, as described by the following positive reports:

We once treated an elder woman who was hospitalized in the sector and required a tomography. Due to the injected contrast, the patient had a CA and then we were activated and soon proceeded to care in the radiology sector. So, I consider the factor team's time of arrival was very important to benefit the patient with fast, high-quality service (N8).

(...) This case I have reported shows great efficiency. From what I recall, our arrivals at the sector never had any delay. We always managed to get there quickly. We are used to urgencies and emergencies. In our daily work, we deal with many kinds of complication, so I believe that our approach in this case in the hospitalization unit was very quick (P13).
Response time in RRT arrival in the unfolded situations was appropriate, for the professionals ensured prompt service and recovery of patients undergoing clinical emergencies.

Apart from positive aspects related to RRT time of arrival for emergency attendance in nursing wards, negative examples have also been revealed:

As a negative example, I can mention a situation where we were activated in a different building, the new one. We had to care for a cardiac arrest and the doctor took long to come to the ward (...) We had monitored the patient, initiated thorax compressions and ventilation with bag-valve-mask and the patient was in ventricular fibrillation, from what was shown in the monitor graphs. We were in this situation and there was a certain delay in applying the shock and reversing the conditions as soon as possible (N13).

I remember that, in the last service in which I took part, I got to the nursing ward in less than two minutes, it was about a patient having a CA, but the doctor took too long to arrive. Misunderstandings among professionals are rare around here, but his delay had generated even bigger stress in this attendance, since you literally depend on another professional to establish a definitive artificial airway (P7).

As exemplified in the previous reports, time for RRT arrival for emergency care should abide by the goal established by the institution, according to the necessity to review the care process so that the patient is benefitted with fast and qualified service in non-critical hospitalization units.

\section{DISCUSSION}

In the study population, one have observed a relation between recognition of clinical worsening in non-critical inpatients and subsequent activities, such as service activation and rapid response team arrival to provide the patient with emergency care.

Clinical worsening is recognized from changes in the patient's vital parameters routinely monitored by health professionals in hospitalization units ${ }^{(14)}$. Vital signs measurement "is an important indicator of safe care result, and its effective control is influenced by organizational culture of active safety, which must be in accordance with the review of work processes, access to basic measurement materials and, above all, value health professionals who are the main partners of care quality"(15).

Health professionals in hospitalization units must be alert for immediate recognition of patients' clinical worsening (warning signs), so that immediate RRT activation is possible, since decision-making regarding increasing severity of the patient's clinical situation and appropriate team allocation will contribute to increased survival, avoiding $\mathrm{AE}$ occurrence during hospitalization ${ }^{(16-17)}$.

The literature demonstrates that inpatients display warning or clinical instability signs around six to eight hours before having a CA in up to $85 \%$ of cases $^{(18)}$. An Australian study evaluated hospital mortality increase as related to delayed recognition of clinical worsening and RRT activation by professionals ${ }^{(19)}$. 
As a proposal for RRT activation improvement, two American hospitals provided training to health teams in non-critical hospitalization units using simulated emergency care settings with RRT professionals. The simulated event led to an improvement in action aimed at recognizing warning signs and reducing delays in RRT activation, contributing to effective initiation of cardiopulmonary resuscitation ${ }^{(20)}$.

Research conducted in a Brazilian university hospital has concluded that most interviewees affirm that nurses in non-critical hospitalization units play the main role in activating rapid response teams. The nurses working in hospitalization units are considered main allies in RRT activation, since they identify early patient clinical changes during health care provided for 24 hours daily ${ }^{(7)}$.

RRT implementation must be a component of the institution's effort to improve emergency services and promote the secure care demanded by patients. This includes permanent health education, trained nursing team and human and material resources provision to maintain constant service efficiency ${ }^{(21)}$.

Hence, health professionals in hospitals need to be aware and secure regarding their hospital's RRT activation criteria. The literature recognizes the existence of deficient knowledge and the persistence of barriers resulting in delays in RRT activation ${ }^{(22)}$.

A research has analyzed 285 emergency calls to RRT, comparing between two groups: one presenting no activation errors and the other presenting service activation errors. The group with activation problems had a higher rate of CA associated to high immediate mortality. The study reinforces that non-critical hospitalization units need to invest in training health professionals regarding RRT activation criteria ${ }^{(23)}$.

Initial care to patients presenting clinical worsening during hospitalization in nursing wards, along with quick RRT activation by these unit's professionals, sensitively contributed to survival rate. The patient is benefited by the necessary therapeutic intervention in emergency situations, such as $\mathrm{CA}$ events. Nevertheless, delays in activation or the non-activation of the RRT may lead to severe harm to their health ${ }^{(24)}$.

A study conducted in a high-complexity school hospital shows that the quality index for time between activation and arrival of RRT professionals ranges from approximately one to three minutes ${ }^{(25)}$. The aspect time until RRT professional's arrival at the hospitalization unit is proportionately essential to patient survival rate, which makes it an important quality index for this service.

According to the American Heart Association ${ }^{(26)}$, acting quickly is essential and relates directly to the best patient prognosis, with an improvement in their survival, in addition to reduction of irreversible brain lesion. Such a statement corroborates the findings of a study conducted in an Asian hospital, which pointed that average RRT arrival time for emergency care was 1.6 minutes, with the first shock administered for shockable rhythm conducted in up to two minutes, and the first dose of endovenous adrenaline was administered within 2.7 minutes ${ }^{(27)}$.

Time is a crucial and determinant variable regarding care of CA victims. It is estimated that for each minute in which the patient receives no care from health professionals trained to conduct cardiopulmonary resuscitation, survival is reduced by $10 \%$. Hence, detection and fast care become important to enable high-quality resuscitation with no irreversible harm ${ }^{(26)}$.

Thus, reflections on the reasons that characterize negative situations are necessary, according to perceptions of professionals acting in RRT from the two study institutions, to enable improvements in recognition of the patient's clinical worsening in the nursing wards, fast service activation and ideal arrival time, contributing with high-quality safe care to hospitalized patients.

As a study limitation, results are highlighted as representing the perception of different professional categories integrating the RRT of a public hospital and a philanthropic hospital located in a municipality in Paraná state's countryside and the city of São Paulo. This selection does not enable result generalization, meaning future research, with a broader population, is necessary to determine whether critical requirements established were satisfactory in characterizing emergency services provided by RRT in hospitals.

Nevertheless, this study may contribute to the advancement of evaluation of care performed by RRT in Brazilian hospitals, considering the scarcity of qualitative research dealing with this theme in Brazil. It enables setting improvement strategies in care provided to patients evolving to clinical condition worsening in non-critical hospitalization units, hence contributing to patient safety coverage in diverse health institutions in both Brazil and the world.

\section{CONCLUSION}

The prime function of the RRT is contributing to the safe care of patients hospitalized in non-critical units. This service, when activated by the unit's professional, aims to provide care with quick and efficient intervention during sudden, unexpected patient clinical deterioration; consequently, it is a manner of preventing its evolution to an unfavorable clinical outcome.

Cardiac arrest was a predominant condition among the emergencies reported by interviewed professionals. This may be correlated, since it presents high mortality rate. It is a dramatic situation, demanding highly qualified staff aiming at avoiding possible health harm and the high probability of mortality; this can be favored by a work process including a multiprofessional qualified team, with due resources and proper infrastructure to provide emergency care.

The RRT contributes to patient safety in the hospital environment, since it provides care to prevent $\mathrm{AE}$ in patients hospitalized outside the ICU. Considering the identification of positive and negative critical incidents reported by nurses, physiotherapists and doctors, it was possible to recognize facile and difficult experiences of such professionals during emergency care.

Even accounting for the difficulties faced by these professionals during care to patients who evolve to critical conditions in hospitalization units, positive reports have been predominant in all categories. These validate the importance of RRT implementation in both health institutions as a contribution to quality and safety of patients presenting $\mathrm{AE}$ during hospitalization. 


\section{RESUMO}

Objetivo: Analisar os atendimentos de emergência na perspectiva dos profissionais dos times de resposta rápida em dois hospitais, sendo um público e um filantrópico, diante de incidentes críticos positivos e negativos. Método: Estudo descritivo, exploratório, de abordagem qualitativa, realizado com 62 profissionais de saúde. Utilizou-se a Técnica do Incidente Crítico como referencial teóricometodológico e, para análise dos dados, a análise de conteúdo. Resultados: Participaram 62 profissionais de saúde, sendo 23 enfermeiros, 20 fisioterapeutas e 19 médicos. Obteve-se o agrupamento de 89 incidentes críticos, sendo 66 considerados positivos e 23 negativos. As situações relacionadas aos atendimentos realizados pelos serviços foram classificadas em três categorias, a saber: o reconhecimento da deterioração clínica do paciente; o acionamento do time de resposta rápida na unidade; e o tempo de chegada do time de resposta rápida à enfermaria. Conclusão: Destaca-se que, apesar das dificuldades enfrentadas por esses profissionais durante os atendimentos aos pacientes que se tornam graves nas unidades de internação não críticas, predominaram relatos positivos nas três categorias, que legitimaram a importância do serviço como contribuição à qualidade e segurança dos pacientes hospitalizados.

\section{DESCRITORES}

Equipe de Respostas Rápidas de Hospitais; Parada Cardíaca; Reanimação Cardiopulmonar; Enfermagem em Emergência; Segurança do Paciente.

\section{RESUMEN}

Objetivo: Analizar las atenciones de emergencia en la perspectiva de los profesionales de los equipos de respuesta rápida en dos hospitales, siendo uno público y otro filantrópico, ante incidentes críticos positivos y negativos. Método: Estudio descriptivo, exploratorio, con abordaje cualitativo, realizado con 62 profesionales de salud. Se utilizó la Técnica del Incidente Crítico como propuesta teóricometodológica y, para el análisis de los datos, el análisis de contenido. Resultados: Participaran 62 profesionales de salud, siendo 23 enfermeros, 20 fisioterapeutas y 19 médicos. Se obtuvo el agrupamiento de 89 incidentes críticos, siendo 66 considerados positivos y 23 negativos. Las situaciones relacionadas a las atenciones realizadas por los servicios fueron clasificadas en tres categorías, a saber: el reconocimiento del deterioro clínico del paciente; la activación del equipo de respuesta rápida en la unidad; y el tiempo de llegada del equipo de respuesta rápida al pabellón. Conclusión: Se destaca que, a pesar de las dificultades que enfrentan los profesionales durante la atención a pacientes que sufren deterioro en las unidades de cuidados no críticos, predominaran informes positivos en las tres categorías, que muestran la importancia del servicio como una contribución a la cualidad y seguridad de los pacientes hospitalizados.

\section{DESCRIPTORES}

Equipo Hospitalario de Respuesta Rápida; Paro Cardíaco; Reanimación Cardiopulmonar; Enfermería de Urgencia; Seguridad del Paciente.

\section{REFERENCES}

1. World Health Organization. Patient safety research: introductory course - Session 1. What is patient safety? [Internet]. Geneva: WHO; 2012 [cited 2017 Dec 27]. Available from: http://www.who.int/patientsafety/research/online_course/en/

2. Joint Commission on Accreditation of Healthcare Organizations. Facts about patient safety [Internet]. Oakbrook Terrace; 2017 [cited 2017 Mar 23]. Available from: https://www.jointcommission.org/facts_about_patient_safety/

3. Françolin L, Gabriel CS, Bernardes A, Silva AEBC, Brito MFP, Machado JP. Patient safety management from the perspective of nurses. Rev Esc Enferm USP. 2015;49(2):277-283. DOI: http://dx.doi.org/10.1590/S0080-623420150000200013

4. Mendes W, Pavão ALB, Martins M, Moura MLO, Travassos C. Características de eventos adversos evitáveis em hospitais do Rio de Janeiro. Rev Assoc Med Bras [Internet]. 2013 [citado 2018 jan. 14];59(5):421-8. Disponível em: http://www.scielo.br/scielo.php?script=sci_ arttext\&pid=S0104-42302013000500006\&lng=en

5. Institute for Healthcare Improviment. 5 Million Lives Campaign. Getting started kit: rapid response team how to guide [Internet]. San Francisco; 2017 [cited 2018 Feb 06]. Available from: http://www.ihi.org/Engage/Initiatives/Completed/5MillionLivesCampaign/Pages/ default.aspx

6. Devita MA, Hillman K, Bellomo R. Textbook of rapid response systems: concepts and implementation. RRS's general principles. New York: Springer; 2011.

7. Dias AO, Grion CMC, Martins EAP. Quality analysis of the rapid response team in a university hospital: nurses'opinions [Internet]. Ciênc Cuid Saúde 2015 [cited 2018 Jan 30];14(1):917-923. Available from: http://periodicos.uem.br/ojs/index.php/CiencCuidSaude/article/ view/22919/pdf_314

8. Gonçalves PDS, Polessi JA, Bass LM, Santos GPD, Yokota PKO, Laselva CR, et al. Redução de paradas cardiorrespiratórias por times de resposta rápida. Einstein. 2012;10(4):44-8.

9. Angel M, Ghneim M, Song J, Brocker J, Tipton PH, Davis M. The effects of a rapid response team on decreasing cardiac arrest rates and improving outcomes for cardiac arrests outside critical care areas. Medsurg Nurs. 2016;25(3):153-9.

10. Jung B, Daurat A, Dejong A, Chanques G, Mahul M, Monnin M, et al. Rapid response team and hospital mortality in hospitalized patients. Intensive Care Med. 2016;42(4):494-504.

11. Flanagan JC. A técnica do incidente crítico. Arq Bras Psic Aplic. 1973;25(2):99-141.

12. Dela Coleta JA, Dela Coleta MF. A técnica dos incidentes críticos: 30 anos de utilização no Brasil, na psicologia, administração, saúde e educação. Taubaté: Cabral; 2004.

13. Minayo MCS. O desafio do conhecimento: pesquisa qualitativa em saúde. 12a ed. São Paulo: Hucitec; 2010.

14. Offner PJ, HEIT J, Roberts R. Implementation of a rapid response team decreases cardiac arrest outside of the Intensive Care Unit. J Trauma. 2007;62(5):1223-38.

15. Teixeira CC, Boaventura RP, Souza ACS, Paranaguá TTB, Bezerra ALQ, et al. Vital signs measurement: an indicator of safe care delivered to elderly patients. Texto Contexto Enferm [Internet]. 2015 [cited 2017 Ago 17];24(4):1071-8. Available from: http://www.scielo.br/pdf/ tce/v24n4/pt_0104-0707-tce-24-04-01071.pdf 
16. Walston JM, Cabrera D, Bellew SD, Olive MN, Lohse CM, Bellolio MF. Vital signs predict rapid-response team activation within twelve hours of emergency department admission. West J Emerg Med. 2016;17(3):324-30.

17. Simpson E. In-hospital resuscitation: recognising and responding to adults in cardiac arrest. Nurs Stand. 2016;30(51):50-63.

18. Jones D, Drennan K, Hart GK, Bellomo R, Web SAR. Rapid response team: composition, resourcing and calling criteria in Australia. Resuscitation. 2012;83(5):563-67.

19. Le Guen MP, Tobin AE, Reaid D. Intensive care unit admission in patients following rapid response team activation: call factors, patient characteristics and hospital outcomes. Anaesth Intensive Care. 2015;43(2):211-5.

20. Yager P, Collins C, Blais C, O'Connor K, Donovan P, Martinez M, et al. Quality improvement utilizing in-situ simulation for a dual-hospital pediatric code response team. Int J Pediat Otorhinolaryngol. 2016;88:42-6.

21. McCurdy MT, Wood SL. Rapid response systems: identification and management of the "prearrest state". Emerg Med Clin North Am. 2012;30(1):141-52.

22. Coventry C, Flabouris A, Sundararajan K, Cramey T. Rapid response team calls patients with a pre-existing not for resuscitation order. Resuscitation. 2013;84(8):1035-9.

23. Barbosa V, Gomes E, Vaz S, Azevedo G, Fernandes G, Ferreira A, et al. Failure to activate the in-hospital emergency team: causes and outcomes. Rev Bras Ter Intensiva [Internet]. 2016 [cited 2017 Mar 28];28(4):420-6. Available from: http://www.scielo.br/scielo. php?script=sci_arttext\&pid=S0103-507X2016000400420\&lng=en\&nrm=iso\&tlng=en

24. Tirkkonen J, Yla-Mattila J, Olkkola KT, Huhtala H, Tenhunen J, Hoppu S. Factors associated with delayed activation of medical emergency team and excess mortality: an Utstein-style analysis. Resuscitation. 2013;84(2):173-8.

25. Santana-Santos E, Bezerra DG, Alberto MR, Ferreira FG, Palomo JSH, Silva CCB, et al. Perfil de atendimentos do código azul em um hospital escola especializado em cardio- pneumologia. Rev Cubana Enferm [Internet]. 2017 [citado 2017 mar. 21];33(1). Disponível em: http://www.revenfermeria.sld.cu/index.php/enf/article/view/705/231

26. American Heart Association. Destaques das Diretrizes da American Heart Association para RCP e ACE. Guidelines 2015 [Internet]. Washington: AHA; 2015 [citado 2017 dez. 17]. Disponível em: https://eccguidelines.heart.org/wp-content/uploads/2015/10/2015-AHAGuidelines-Highlights-Portuguese.pdf

27. Eftychiou C, Georgiou M, Andreou A, Michaelides A, Yiangou K, Deligeorgis A, et al. Nicosia General Hospital cardiac arrest team: first year's practice and outcomes of in-hospital resuscitation. Hellenic J Cardiol. 2009;50(4):264-8. 